\title{
Eddy heat diffusion and Subantarctic Mode Water formation
}

\author{
J.-B. Sallée, ${ }^{1}$ R. Morrow, ${ }^{1}$ and K. Speer ${ }^{2}$ \\ Received 28 November 2007; revised 8 January 2008; accepted 6 February 2008; published 11 March 2008.
}

[1] Subantarctic mode waters (SAMW) form in the deep winter mixed layers occuring north of the Subantarctic Front (SAF). The recent increase of hydrographic and surface drifter data in the Southern Ocean allows a better spatial representation of the distinct regions of SAMW formation. This study focuses on the thermodynamical processes acting on the winter mixed layer heat budget. Eddy heat diffusion play a substantial role in the local heat balance, whereas its action vanishes with large-scale averaging. South of the western boundary currents and north of the SAF, the eddy heating plays an important role in specific regions, counterbalancing the cooling of the mixed layer by Ekman advection and air-sea fluxes. Specifically, the eddy diffusion term reduces the tendency for mixed layer destabilisation north of the SAF in the Western Indian Ocean downstream of the Agulhas Retroflection and in the Western Pacific downstream of Campbell Plateau. This role for mixed layer eddy fluxes emphasizes a large-scale control of mixed layer properties by topography and mesoscale processes in the Southern Ocean. Citation: Sallée, J. B., R. Morrow, and K. Speer (2008), Eddy heat diffusion and Subantarctic Mode Water formation, Geophys. Res. Lett., 35, L05607, doi:10.1029/2007GL032827.

\section{Introduction}

[2] Subantarctic mode water (SAMW) is the water mass formed in the very deep winter mixed layers (MLs) found directly north of the Subantarctic Front (SAF) in the Southern Ocean. Mode waters are a primary result of airsea interaction [Speer et al., 1995] and act to ventilate the interior of the upper ocean as they spread into gyres [McCartney, 1982; Hanawa and Talley, 2001]. These oxygen-rich layers can persist to the tropics [McCartney, 1982]. Since SAMW occupies a large area in direct contact with the atmosphere during winter, it is very sensitive to climate change [Sabine et al., 2004]. A better understanding of the processes controlling the SAMW formation is a key requirement for climate studies.

[3] Figure 1a shows the winter ML depth in the Southern Ocean deduced from ship data and 5 years of Argo data superimposed on the mean Antarctic Circumpolar Current (ACC) fronts. Although the winter sampling is not perfect, the large-scale circumpolar structure is striking. Previous studies have emphasized the substantial role of air-sea fluxes and Ekman fluxes in controlling the destabilisation of the winter ML in which SAMW is renewed [Speer et al.,

\footnotetext{
${ }^{1}$ LEGOS, Toulouse, France.

${ }^{2}$ Department of Oceanography, Florida State University, Tallahassee, Florida, USA.
}

Copyright 2008 by the American Geophysical Union. 0094-8276/08/2007GL032827
1995; Rintoul and England, 2002]. Recently, the new Argo dataset has allowed a more detailed vision of the water column evolution over all seasons [Sallée et al., 2006; Dong et al., 2007]. These observational studies have supported the basic idea that the heat content variation of the ML can be explained to first order by the action of air-sea heat fluxes and Ekman heat transport.

[4] However, locally the action of the Ekman and air-sea fluxes can be modified by eddy heat diffusion, which can heat or cool SAMW [Sallée et al., 2006] (hereinafter referred to as SWMS06). While SWMS06 focussed on the Indian Ocean sector, we propose that this eddy flux exerts a control on the overall large-scale structure of the deep mixed layers that form the SAMW. We proceed to examine this hypothesis in another key region of mixed layer evolution in the southwest Pacific sector.

[5] In this paper we aim to understand the cause of the sudden shallowing of the winter MLs in the Subantarctic Zone that occurs downstream of the Campbell Plateau near $170^{\circ} \mathrm{E}$ in the western South Pacific (see Figure 1a). We compute the different terms of the heat equation to compare their relative importance. Based on previous Southern Ocean heat budget studies [Jayne and Marotzke, 2002; Rintoul and England, 2002; Dong et al., 2007; SWMS06] we focus on three main forcing terms: air-sea fluxes, Ekman transport, and eddy diffusion. New estimates of the eddy diffusion coefficient have now emerged from the Global Drifter Program (GDP) surface drifter dataset. Studies suggest that eddy diffusion in the Southern Ocean is strong, especially in the western boundary currents [Zhurbas and Oh, 2004; J. B. Sallée et al., An estimate of Lagragian eddy statistics and diffusion in the mixed layer of the Southern Ocean, submitted to Journal of Marine Research, 2007]. These new estimates of surface eddy diffusivity are of the order of $10^{4} \mathrm{~m}^{2} \mathrm{~s}^{-1}$ in the western boundary areas which could produce a strong impact on a local ML heat budget.

[6] We will consider the winter climatological forcing over the Southern Ocean, and its impact on the winter MLs (sections 3 and 4). We will also investigate the ML evolution in the southwest Pacific using a time series of instantaneous Argo profiles (section 5). Our aim is to establish whether or not the SW Pacific undergoes SAMW formation processes comparable to the SW Indian ocean (SWMS06).

\section{Data and Methods}

\subsection{Heat Budget Equation}

[7] Previous studies suggest that Ekman advection and air-sea fluxes are the dominant terms in destabilizing the winter water column to create the strong and deep convection observed [Rintoul and England, 2002; Dong et al., 2007; SWMS06]. In the present study we focus on these two forcing terms as well as the eddy heat diffusion 
a)

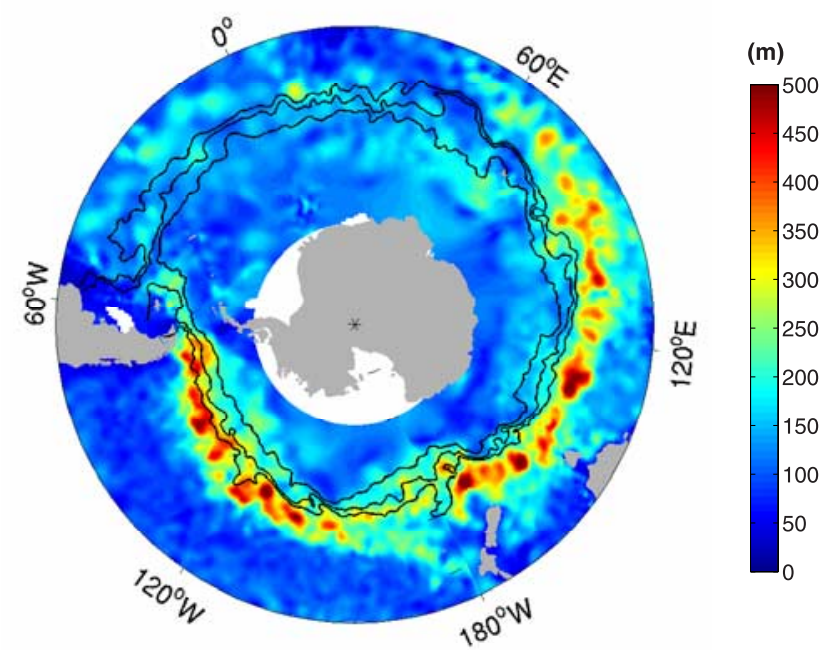

b)

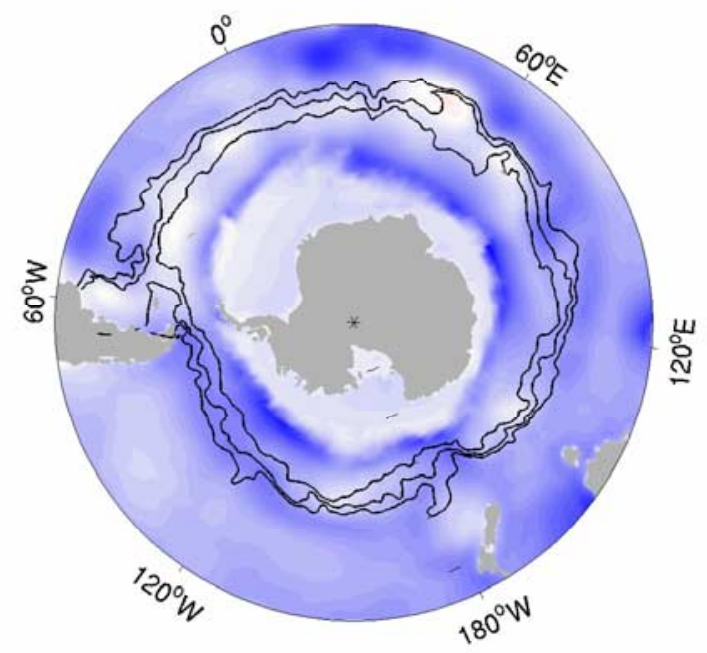

d)

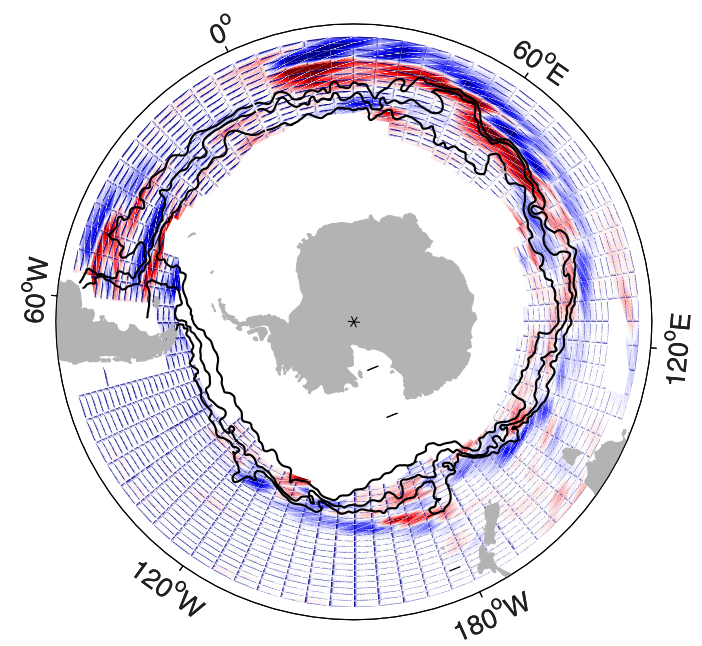

c)

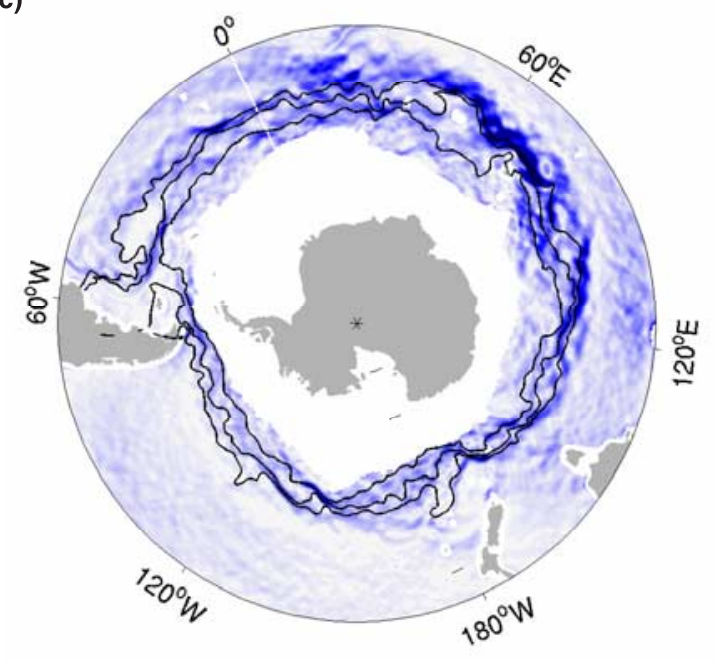

e)

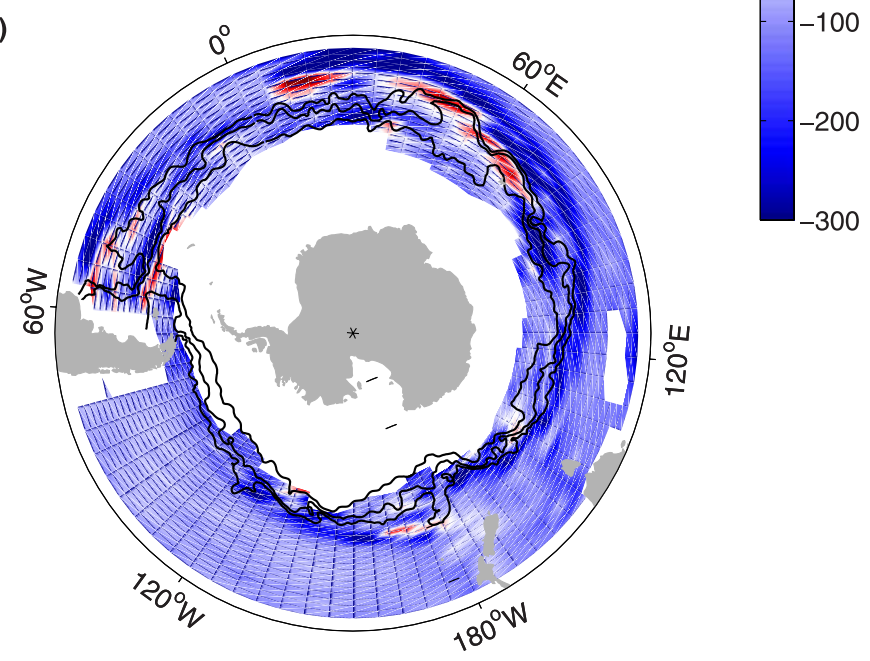

Figure 1. (a) Winter mixed layer depth in the Southern Ocean from Argo and ship data, (b) climatological winter air-sea heat exchange, (c) Ekman heat advection, (d) eddy heat diffusion in the mixed layer and (e) the total of these three components. Contours represent the mean ACC fronts (PF, SAF and SAF-N). 
contribution. Therefore, we consider the simplified heat budget equation:

$$
\frac{\partial T}{\partial t}=\frac{Q_{0}}{\rho C_{p} \cdot h}-u_{e k} \cdot \nabla T+\nabla\left(\kappa_{h} . \nabla T\right)
$$

where $h$ is the layer thickness, $T$ the mean ML temperature, $u_{e k}$ the Ekman velocity vector, $Q_{0}$ the total heat flux at the ocean surface, and $\kappa_{h}$ the (annual mean) horizontal eddy diffusion coefficient in the ML. We estimated each term of the equation from the data presented below.

\subsection{Data}

[8] To estimate the air-sea heat flux we use the JRA-25 reanalysis data (http://jra.kishou.go.jp). This recent reanalysis includes more observational data than the other reanalysis product [Onogi et al., 2007]: hence we believe it better represents synoptic and meso-scale features. We have compared the climatological mean air-sea fluxes from JRA-25 with those from ECMWF (ERA-40) and NCEP (V1). The colocated standard deviation of these 3 mean heat flux products ranges from 0 to $40 \mathrm{~W} \mathrm{~m}^{-2}$ with minimum differences around the ACC. The average standard deviation of these climatological fluxes over the area studied here $(-60 /-35 \mathrm{~S})$ was only $6 \mathrm{~W} \mathrm{~m}^{-2}$.

[9] Wind stress are from the high-resolution monthly Quickscat data (http://www.ifremer.fr/cersat/), with a stated error of less than $7.10^{-3} \mathrm{~Pa}$ over the area studied. Surface temperature is from the global satellite SST product from TMI and AMSR satellites (http://www.ssmi.com/). Given that the area studied is mainly outside the boundary of TMI satellite, most of the data are from the AMSR-E satellite. When compared to MODIS or Reynolds OI SST, AMSR-E SST have less bias relative to in-situ observations. A comparison of AMSR-E SSTs with XBT repeated sections shows that the standard error is less than $0.1 \mathrm{C}$ during winter [Dong et al., 2006]. Combined with the wind stress error this results in an Ekman heat transport error of approximately $20 \mathrm{~W} \mathrm{~m}^{-2}$ over the studied area.

[10] The annual mean climatological cross-stream eddy diffusivity coefficient has been estimated in bins of $5^{\circ}$ longitude by $1^{\circ}$ latitude for the Southern Ocean by Sallée et al. (submitted manuscript, 2007). This coefficient results from a statistical formulation, computed using 10 years (1995-2005) of surface drifter data. On average over the circumpolar belt, the diffusivity shows an increase from the Antarctic continent to the ACC, a stable plateau around $4000 \mathrm{~m}^{2} \mathrm{~s}^{-1}$ within the ACC and a further increase north of the ACC dominated by the western boundary current regions.

[11] The mean circulation and fronts of the Southern Ocean are deduced from a climatology of Sea Surface Height (SSH) referenced to $1500 \mathrm{~m}\left(\mathrm{SSH}_{1500 \mathrm{~m}}\right)$ following Sallée et al. [2008]. The Polar Front (PF) is associated with the $0.95 \mathrm{~m} \mathrm{SSH}_{1500 \mathrm{~m}}$ contour; the Subantarctic Front (SAF) with $S_{S H} H_{1500 m}=1.2 \mathrm{~m}$; and the northern branch of the Subantarctic Front (SAF-N) with $S_{S S H} H_{1500 m}=1.35 \mathrm{~m}$.

[12] The ocean interior characteristics are obtained using the Argo dataset (www.argo.ucsd.edu) and the Southern Ocean database (SODB) (http://wocesoatlas.tamu.edu/). Databases of ML depth and $S S H_{1500 m}$ have been extracted from these datasets and then gridded using a loess fitting method. Following de Boyer Montégut et al. [2004] and SWMS06, we used a density difference criteria of $0.03 \mathrm{~kg} \mathrm{~m}^{-3}$ to assess the ML depth of each profile.

\section{SAMW Formation Pool}

[13] Figure 1a shows the winter (July to September) ML depth in the Southern Ocean. This maximum ML depth pattern is similar to previous studies [Talley, 1999; de Boyer Montégut et al., 2004]. However, the Argo dataset provides a large amount of data in winter and in the middle of the gyres [Sallée et al., 2008]. Thus, for the first time, we have enough confidence in the winter climatology to confirm that the very deep MLs (up to $600 \mathrm{~m}$ ) shoals as the flow rounds the Campbell Plateau. Shallower winter MLs continue up to the Eltanin Fracture Zone in the midPacific Ocean $\left(230^{\circ} \mathrm{E}-130^{\circ} \mathrm{W}\right)$.

[14] Deep winter MLs are clearly linked to the circulation, as they occur directly north of the SAF-N in the Indian sector and directly north of the SAF in the Pacific sector. Upstream of Drake Passage the deepest MLs occur further south, just north of the PF. In the southern Indian sector, SWMS06 have shown the role of the circulation and the eddy heat diffusion on the MLs. Can we infer a similar role in the Pacific sector?

\section{Climatological Heat Forcing and Circulation}

[15] Based on the datasets presented in section 2, we computed the three climatological winter forcing terms on the right of the simplified heat budget equation (equation (1)). The winter air-sea fluxes in Figure $1 \mathrm{~b}$ cool the Southern Ocean everywhere, with maximum cooling occurring north of the sea ice and north of the SAF fronts. Stronger cooling occurs across the fronts downstream of Kerguelen around $90^{\circ} \mathrm{E}$, around the Campbell Plateau at $170^{\circ} \mathrm{E}$, and in the SE Pacific. The Ekman heat transport in Figure 1c is driven by the strong westerly winds, transporting cold water equatorward, resulting in a general loss of heat everywhere around the circumpolar belt. The eddy heat diffusion (Figure 1d) is the annual climatological mean, which should be similar to the winter mean. Eddies diffuse heat from the warm equatorward side of a temperature gradient to the cool poleward side; hence, the eddy heat diffusion generally cools the northern side of the SAF and SAF-N and heats the southern side. However, departures from this general shape are locally observed when a powerful western boundary current associated with a substantial SST gradient interacts with the ACC or near topography. Thus, warming on the north side of the ACC is observed in the Southwestern Indian sector between the longitudes $30-60^{\circ} \mathrm{E}$ (SWMS06), downstream of the Campbell Plateau $\left(170^{\circ} \mathrm{E}\right)$, and near the Brazil-Malvinas current $\left(40^{\circ} \mathrm{W}\right)$.

[16] Once the ACC rounds the Campbell Plateau, the flow divides into two branches. The Southern branch includes the PF and SAF, which flows southward hugging the Indo-Pacific Ridge. The northern branch is the SAF-N, which turns sharply to the north following the southern flank of the Campbell Plateau until approximately $50^{\circ} \mathrm{S}$. The two branches then merge to pass through the Eltanin Fracture Zone $\left(230^{\circ} \mathrm{E}-130^{\circ} \mathrm{W}\right)$. As the SAF-N rounds the 
Campbell Plateau, it enters a region of weak winter air-sea cooling and positive eddy heat diffusion (Figures $1 \mathrm{~b}$ and 1d). For the Southern branch, the eddy heat diffusion is negative, with stronger Ekman and air-sea fluxes: this cools the north side of the SAF and PF.

[17] The general shape of the eddy heat transport agrees well with the studies of Jayne and Marotzke [2002]. Although the diffusion can be strong locally, on a large scale average its contribution vanishes. Therefore, our results are not contradictory with previous large-scale heat budget estimation that succeeded in closing the heat budget while neglecting the eddy diffusion contribution [Dong et al., 2007; SWMS06].

[18] Figures $2 \mathrm{a}$ and $2 \mathrm{~b}$ shows the winter average of the sum of the three forcing terms (i.e. Figure 1e) and the winter ML depth, but now in alongstream coordinates relative to the position of the SAF-N. Also shown is the winter ML density for MLs greater than $200 \mathrm{~m}$ depth (Figure 2c). Strong cooling north of the SAF-N coincides with the regions of deep winter MLs in the Subantarctic Zone. Strong cooling also occurs south of the SAF-N in three regions: downstream of Kerguelen around $90^{\circ}-100^{\circ} \mathrm{E}$, downstream of New Zealand near $170-190^{\circ} \mathrm{E}$, and in the South Pacific from $240-260^{\circ} \mathrm{E}\left(100-120^{\circ} \mathrm{W}\right)$. These are the only regions with a deep winter ML south of the SAF-N (Figure 2b), and have much denser MLs, exceeding 27.2 in the south Pacific (Figure 2c). The deep winter MLs continue north of the SAF-N in these zones, except for the region downstream of Campbell Plateau. Here, we observe an average winter warming of the area north of the SAF-N, related to stronger eddy diffusion and weaker air-sea cooling (Figures $1 \mathrm{~b}$ and $1 \mathrm{~d}$ ). SWMS06 have shown that this warming prevents the formation of deep winter MLs north of the SAF in the western Indian sector. Figure 2 suggests that a similar process occurs downstream of Campbell Plateau. The substantial eddy diffusion of the region induces a strong cooling north of the Southern branch of the ACC composed of the SAF and PF. Consequently, diffusion tends to prevent deep ML formation north of the SAF-N, but enhances deep MLs north of the SAF. It results in a densification of SAMW downstream of Campbell Plateau (Figure 2c), where oxygen-rich deep MLs attain the density class of 27.1-27.2, usually associated with Antarctic Intermediate Water (AAIW).

\section{Water Column Evolution}

[19] By chance an Argo float drifted along the SAF-N downstream of the Campbell Plateau during the winter of 2006. The water column had undergone a typical seasonal cycle, with a minimum in ML depth of around $50 \mathrm{~m}$ during summer and a deepening in winter (Figure 3c). The winter MLs reached a depth of approximately $250 \mathrm{~m}$ and a potential density of around $26.9 \mathrm{~kg} \mathrm{~m}^{-3}$ during July which corresponds to the SAMW density class. Interestingly, the ML suddenly restratified in the middle of the winter, during the month of August, with the float still close to the front. We computed the terms on both sides of our simplified equation (1) to examine the evolution of the forcing terms, and determine the reason for this sudden and surprising stratification north of the SAF-N during winter. Figure 3d reveals that the water column restratified during the coldest month of winter with continued cooling by the Ekman transport. We note that one has to be careful when tracking water masses with Argo floats, since the float may drift at the surface and sample different water masses between two profiles. However, Figure 3c shows stable deep water masses, and Figure 3d shows that the heat content evolution is consistent with the forcing terms.

[20] The local eddy heat diffusion estimate allows us to explain the observed warming of the water column. We observed two large departures from the balance between heat content variation and the cumulated contributions of Ekman and air-sea fluxes. Both of these departures are qualitatively explained by the sign of the eddy heat diffusion.

[21] From April to July the float drifted in the vicinity of the SAF-N. The eddy diffusion term cooled the water column in this turbulent frontal area during this period (Figures $3 \mathrm{a}$ and $3 \mathrm{~b}$ ). In August, the float drifts east of New-Zealand, north of the SAF-N, in the region of inferred heating by eddy diffusion.

[22] Figure 3b shows that the eddy diffusion heat gain is due to a coherent large scale feature that the float cross in late July and August. We note that the eddy heat diffusion calculated here appears strong compared to other terms. This may be an artefact of computing diffusion from a long term, large scale, climatological eddy diffusion coefficient and an instantenous high resolution SST. However, it does provide a first approximation and estimate of the tendency of the eddy heat diffusion in each region.

[23] The Argo-derived ML shoals as the float drifts into this area, with a ML depth decrease consistent with the heating. Note that the strong heaving of isopycnals in September 2006 associated with a second cyclonic eddy are not enough to break the stratification, and the shallower ML remains into spring.

\section{Concluding Discussion}

[24] SAMWs form in the very deep ML occuring every winter north of the ACC [McCartney, 1982]. This deep ML is not evenly distributed around the circumpolar belt. It is widely accepted that there is no subpolar mode water deepening from Drake Passage around to the Kerguelen Plateau [Talley, 1999; de Boyer Montégut et al., 2004]. Mode waters have been detected in the retroflection region, but these are lower density subtropical mode waters. The growing new Argo dataset reveals that the winter MLs between 170 and $230^{\circ} \mathrm{E}\left(140^{\circ} \mathrm{W}\right)$ in the Western Pacific Ocean are much shallower than those upstream or downstream. Moreover, MLs with density similar to AAIW is formed in the southwest Pacific.

[25] Consistent with previous work, we find that the eddy diffusion vanishes when taking a large scale averaging of the ML [Dong et al., 2007]. However, locally its contribution is very important in the energetic western boundary currents and around topography. Winter climatological maps of the net heat forcing, simplified to its air-sea, Ekman and heat diffusion contributions, show a strikingly similar spatial pattern to the winter ML depth. In the SW Pacific and north of the SAF-N, a region of shallow winter ML coincides with warming by the climatological eddy heat diffusion. A time-varying calculation of the ML depth, 
a)

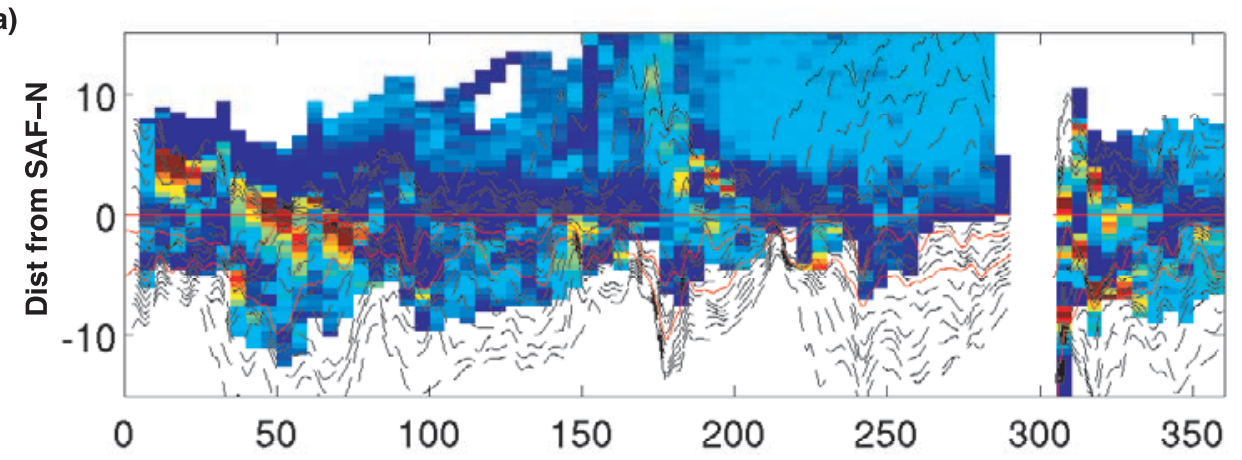

b)

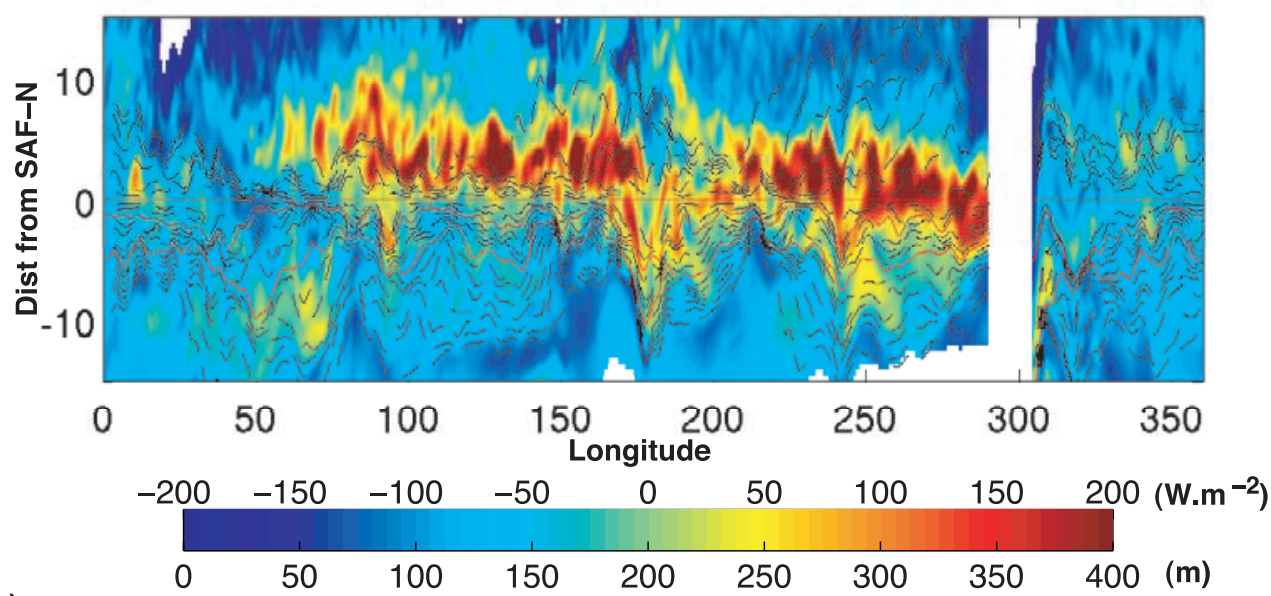

c)

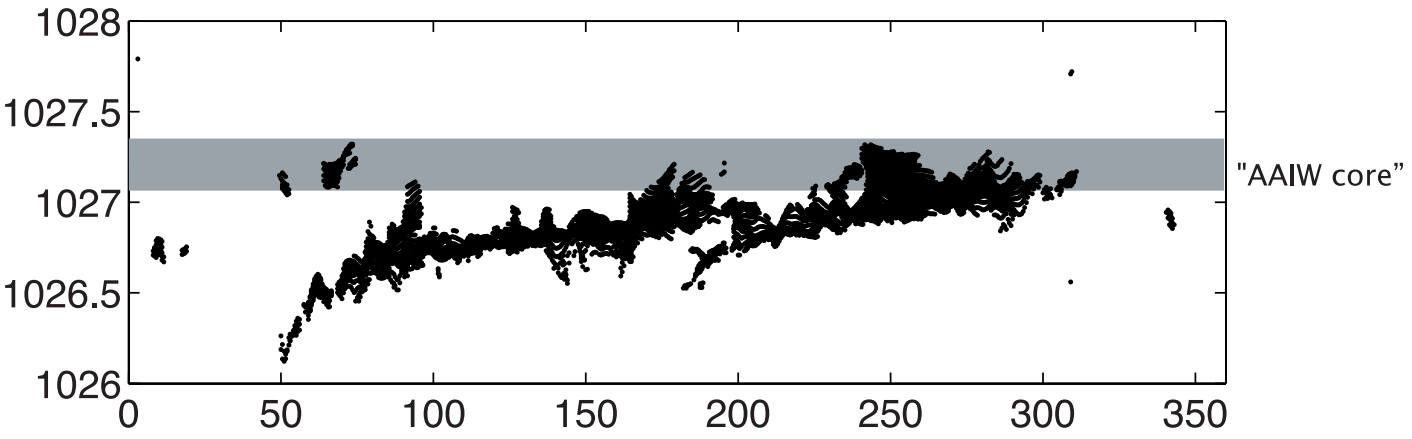

Figure 2. (a) Total of winter air-sea fluxes, Ekman fluxes and eddy diffusion and (b) winter mixed layer depth in streamline coordinates following the SAF-N. Y-axis shows the distance in latitude to the SAF-N. (c) Density class of the winter mixed layer deeper than $200 \mathrm{~m}$. Gray shading indicates the typical AAIW density class. 
a)

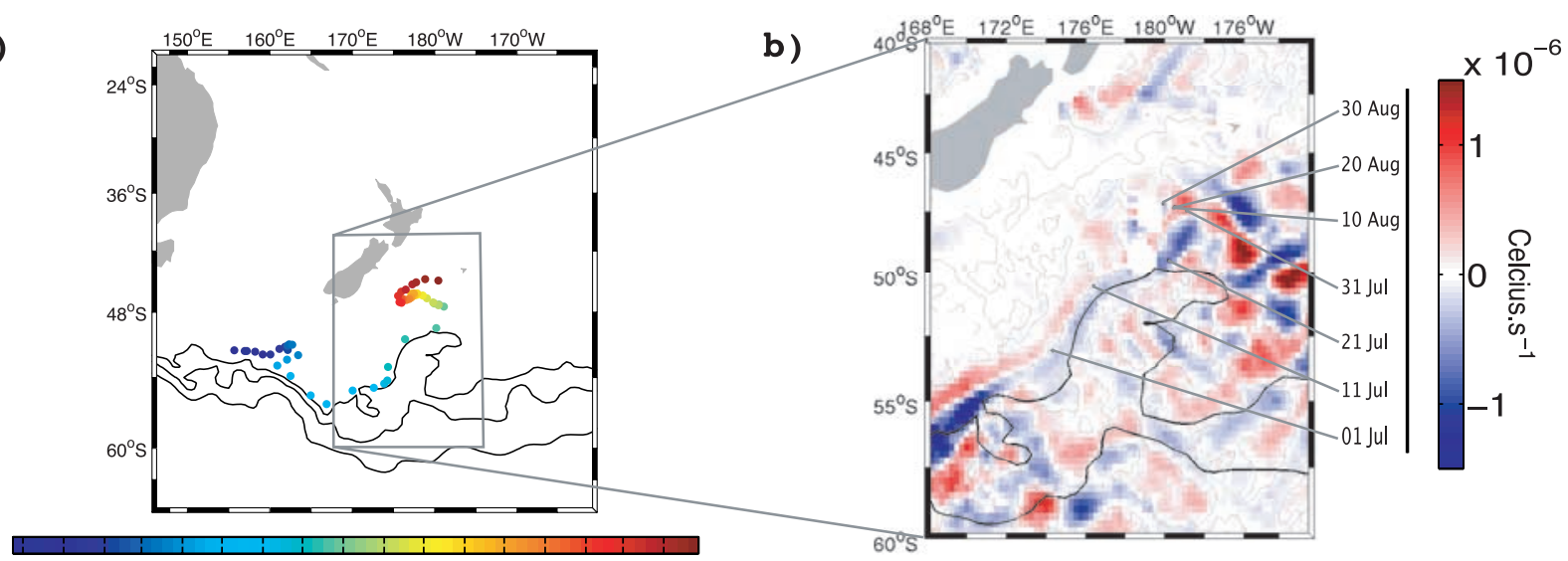

C)

121234567891011121234

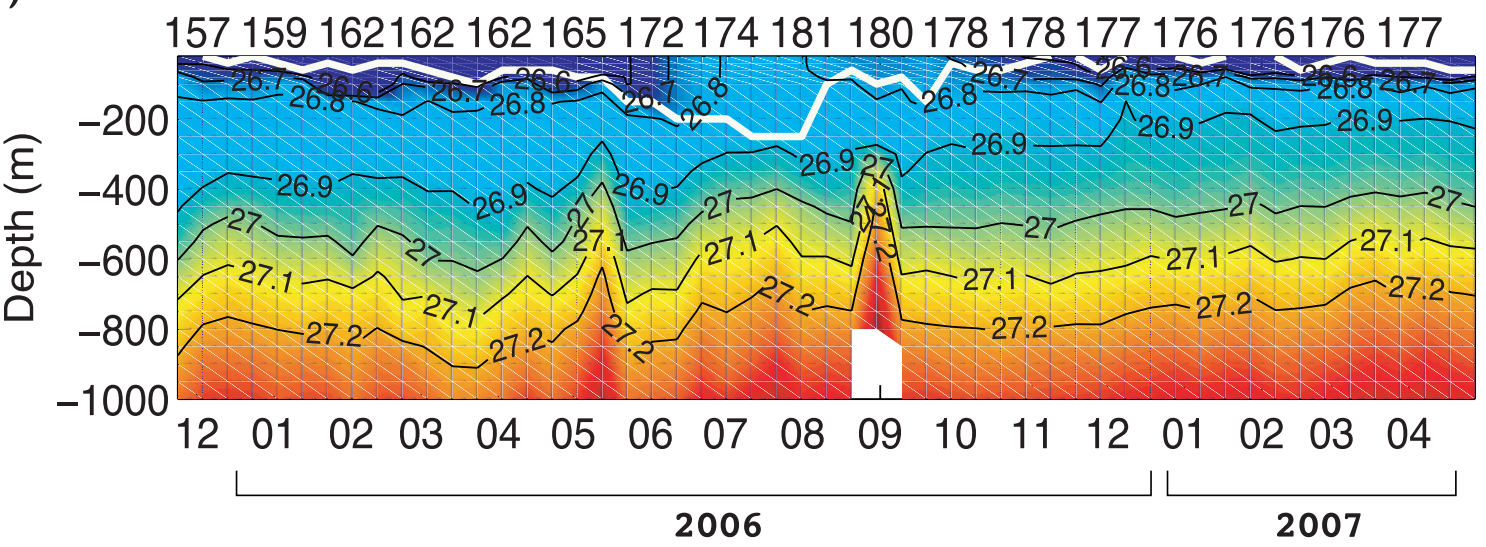

d)

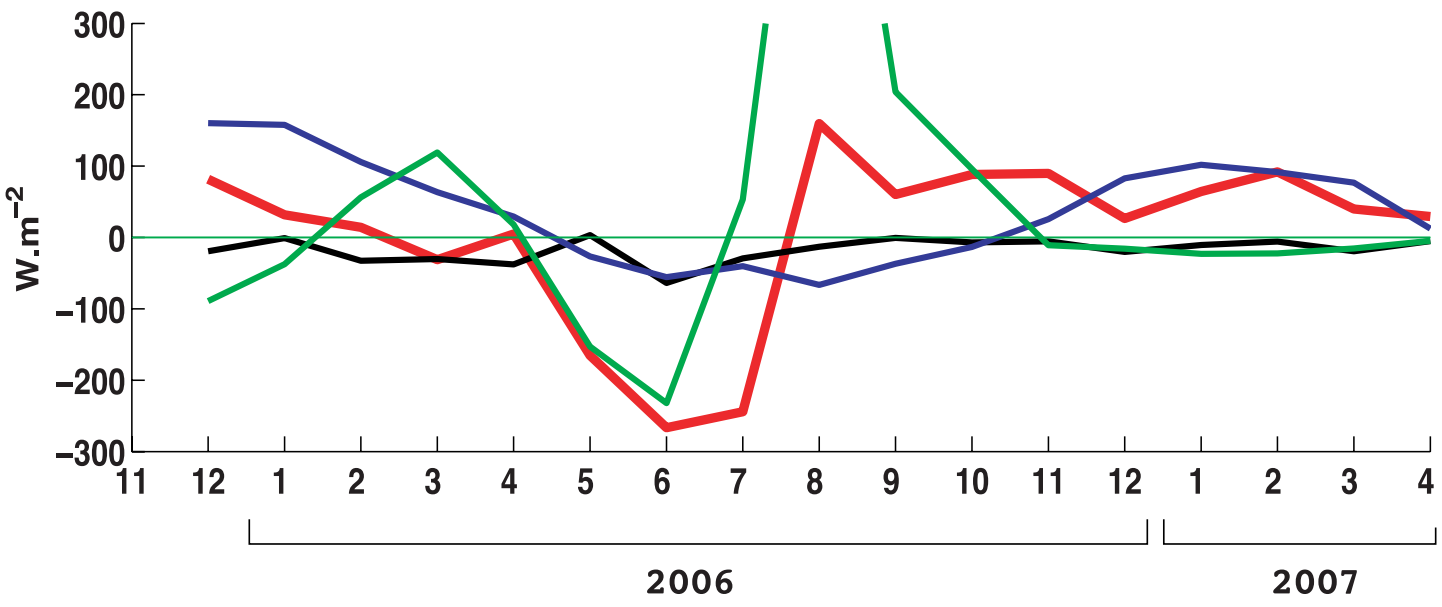

Time

Figure 3. (a) Trajectory of the ARGO float WMO 5901106, with its date in color. Solid lines show the mean position of the SAF-N, SAF and PF. (b) July-August 2006 mean surface heat diffusion and position of the float. (c) Vertical density section along its trajectory over time (bottom x-axis) and longitude (upper x-axis). (d) Monthly averaged simplified heat budget terms along the float trajectory. The red line is the heat content variation computed from the ARGO profiles. Also shown are local air-sea fluxes (blue), Ekman fluxes (black), and eddy heat diffusion (green) along the trajectory. 
following the track of Argo float WMO 5901156, shows a surprising restratification during the coldest month of the year when arriving in this region. This restratification is qualitatively explained by an increase in the eddy heat diffusion.

[26] The sudden change in the circulation of the ACC as it rounds the Campbell Plateau erodes the SAMW north of the SAF-N and enhances formation on the southern side. Cooler and deeper winter MLs thus occur on the equatorward side of the SAF and PF in this area, which are associated with a denser class of SAMW, close to that of AAIW. This suggests a broader definition of AAIW than that in the SE Pacific, where AAIW is thought to form in winter [Hanawa and Talley, 2001]. Changes in eddy energy may have an impact on the SAMW properties and volume, for example a redistribution of AAIW relative to SAMW. This process, in concert with the air-sea interaction could play a role in climate variability.

[27] Acknowledgments. We thank the providers of the free and public data that are used in this study. Argo data were collected and made freely available by the International Argo Project. Ship data were gathered and quality flagged by A. Orsi and T. Whithworth. The research was financed by the French Institute Nationale de la Science de l'Univers via the PATOM and TOSCA programs. KS received support from NSF OCE-0612157.

\section{References}

de Boyer Montégut, C., G. Madec, A. S. Fischer, A. Lazar, and D. Iudicone (2004), Mixed layer depth over the global ocean: An examination of profile data and a profile-based climatology, J. Geophys. Res., 109, C12003, doi:10.1029/2004JC002378.

Dong, S., S. T. Gille, J. Sprintall, and C. Gentemann (2006), Validation of the Advanced Microwave Scanning Radiometer for the Earth Observing
System (AMSR-E) sea surface temperature in the Southern Ocean, J. Geophys. Res., 111, C04002, doi:10.1029/2005JC002934.

Dong, S., J. Sprintall, and S. T. Gille (2007), An assessment of the Southern Ocean mixed layer heat budget, J. Clim., 20, 4425-4442.

Hanawa, K., and L. D. Talley (2001), Mode waters, in Ocean Circulation and Climate, Int. Geophys. Ser, vol. 77, edited by G. Siedler, J. Church, and J. Gould, pp. 373-386, Academic, New York.

Jayne, S. R., and J. Marotzke (2002), The oceanic eddy heat transport, J. Phys. Oceanogr., 32, 3328-3345.

McCartney, M. S. (1982), The subtropical circulation of mode water, J. Mar Res., 40, suppl., 427-464.

Onogi, K., et al. (2007), The JRA-25 reanalysis, J. Meteorol. Soc. Jpn., 85, $369-432$.

Rintoul, S. R., and M. H. England (2002), Ekman transport dominates airsea fluxes in driving variability of subantarctic mode water, J. Phys. Oceanog., 32, 1308-1321.

Sabine, C., et al. (2004), The oceanic sink for anthropogenic $\mathrm{CO}_{2}$, Science, $305,367-371$.

Sallée, J. B., N. Wienders, R. Morrow, and K. Speer (2006), Formation of subantarctic mode water in the southeastern Indian Ocean, Ocean Dyn., $56,525-542$.

Sallée, J. B., R. Morrow, and K. Speer (2008), Response of the Antarctic Circumpolar Current to atmospheric variability, J. Clim., in press.

Speer, K. G., H. J. Isemer, and A. Biastoch (1995), Water mass formation from revised COADS data, J. Phys. Oceanogr., 25, 2444-2457.

Talley, L. D. (1999), Some aspects of ocean heat transport by the shallow, intermediate and deep overturning circulations, in Mechanisms of Global Climate Change at Millennial Time Scales, Geophys. Monogr. Ser., vol. 112, edited by P. U. Clark, R. S. Webb, and L. D. Keigwin, pp. 1-22, AGU, Washington, D. C.

Zhurbas, V., and I. S. Oh (2004), Drifter-derived maps of lateral diffusivity in the Pacific and Atlantic Oceans in relation to surface circulation patterns, J. Geophys. Res., 109, C05015, doi:10.1029/2003JC002241.

R. Morrow and J.-B. Sallée, LEGOS, 14 avenue Edouard Belin, Toulouse F-31400, France. (jbsallee@gmail.com)

K. Speer, Department of Oceanography, Florida State University, 105 N. Woodward Avenue, Tallahassee, FL 32306-4320, USA. 